\title{
The preparedness of newly qualified doctors - Views of Foundation doctors and supervisors
}

\author{
Views on Foundation doctors' preparedness
}

\author{
Joanne Kellett ${ }^{1}$, Alexia Papageorgiou ${ }^{2}$, Penny Cavenagh ${ }^{3}$, Charlotte Salter ${ }^{4}$, Susan Miles ${ }^{4}$, Sam J \\ Leinster $^{4}$
}

\author{
${ }^{1}$ Norfolk and Norwich University Hospital, UK \\ ${ }^{2}$ St George's University of London Medical School at University of Nicosia, Cyprus \\ ${ }^{3}$ University Campus Suffolk, UK \\ ${ }^{4}$ Norwich Medical School, UK
}

Correspondence: Dr Susan Miles. Norwich Medical School, University of East Anglia, Norwich, NR4 7TJ, UK. Tel: 01603 591292. Email: susan.miles@uea.ac.uk

\begin{abstract}
Background: There is evidence that newly qualified doctors do not feel prepared to start work. Aim: This study examined the views of first year Foundation doctors (F1) and supervisors regarding how prepared they felt newly qualified doctors were for the early weeks of work.

Method: Fifty-two F1s took part in a focus group or individual interview during their first year of Foundation training. Twenty-two supervisors took part in an individual interview.

Results: The F1s struggled with new responsibilities, decision-making, time management, prioritising tasks and the large administrative component to their role. They felt unprepared for making diagnoses, prescribing and acting in an emergency. Supervisors felt F1s were generally well prepared to start work, with skills improving through experience. However, F1s needed more practical experience with real patients and more opportunities to take responsibility, make decisions and perform some clinical skills. Supervisors did not feel that F1s accessed senior support appropriately. F1s indicated they preferred to go to peers for assistance in the first instance, and felt unsupported by seniors, particularly at weekends and on night shifts.

Conclusions: Specific areas of unpreparedness were identified by both F1s and supervisors; leading to recommendations to enhance effective transition from medical student to F1.
\end{abstract}

\section{Introduction}

On graduating from medical school trainee doctors in the UK undertake the two year Foundation Programme, where they take increasing responsibility for patient care under supervision. The number of trainee doctors in difficulty is decreasing over time (UKFPO, 2012) and more F1s feel well prepared by their medical school training for their F1 jobs than previously (Goldacre et al., 2010). But, there is evidence that F1s still do not feel adequately prepared to start work in multiple domains (Goldacre et al., 2010; Bleakley \& Brennan, 2011) and find the transition from student to F1 stressful (Brennan et al. 2010; Illing et al., 2008). Whilst they feel prepared for skills like history taking and examination, they feel unprepared for prescribing and dealing with acute care (Illing et al., 2008; Bleakley \& Brennan, 2011; Tallentire et al., 2011a; 2011b). These feelings are matched by actual inadequacies in some areas (Tallentire et al., 2012; Harding et al., 2010). Supervisors find F1s to be ill-prepared in some areas, and less well prepared than F1s themselves believe (Tallentire et al., 2011a; Brown et al., 2010; Matheson \& Matheson, 2009).

There is growing recognition of the importance of considering the unique context of the transition experience separate from the trainee's knowledge, skills and values on starting their new post 
(Kilminster et al., 2011; Teunissen \& Westerman, 2011). Differences in factors such as NHS Trust, speciality, ward/department, consultant preferences for management, team composition and availability of senior support at different times may all affect trainee's experiences during the early days of work. The Foundation Programme requires inductions both at the start of the programme as a whole and at the start of each of the four-month clinical placements. Goldacre et al. (2010) argue that a balance needs to be found "between what is taught in medical school, of immediate relevance to the first job, and what is taught as induction at work in the first job" (p8).

The paper reports on research designed to identify issues relating to the preparedness of newly qualified doctors during the early transition from medical student to F1, as perceived by F1s and supervisors responsible for the training and assessment of F1s.

\section{Methods}

Participants were recruited through the East Anglian Foundation School (EAFS). The EAFS is responsible for the delivery of Foundation training across 12 NHS Trusts, ranging from large teaching hospitals through to smaller specialist regional hospitals. Study details were circulated by email to all F1s ( $n=312$ ) and clinical and educational supervisors of F1s in the Trusts via the EAFS and the Trusts' own Foundation Programme Training Directors. Interested participants contacted the research team to discuss participating. Written and verbal information about the study was provided to all participants and written consent was obtained before commencement of the study. The study obtained NHS ethical approval (10/H0305/7) and Research and Development approval from all the Trusts.

One-to-one and focus group interviews were conducted with F1s registered on the Foundation Programme with the EAFS for the 2010/11 academic year. All data were collected within 6-9 months of the year. Fifty-two F1s took part in the study. This included eight focus groups (with $45 \mathrm{~F} 1 \mathrm{~s} ; 18$ males and 27 females) and seven individual interviews ( 1 male and 6 females). The participants had graduated from a variety of medical schools and were working in medical and surgical specialties across 12 Trusts. Twenty-two qualitative interviews were also conducted with supervisors (16 male and 6 female consultants) across 9 Trusts, from a wide range of the specialities where F1s undergo their training.

Focus groups with F1s took place at their employing Trusts. Recruitment proved challenging and in smaller Trusts where too few doctors were available for a viable focus group, individual interviews took place and the interview guide was adapted to reflect the altered dynamics. Interviews lasted an average of 47 (focus groups) and 45 (one-to-one) minutes; range 30-60 minutes. A semistructured interview guide was used to gather views on: how prepared they felt; challenges encountered; sources of advice and support; and, strengths and weaknesses of their undergraduate training and the induction programme in the light of their early weeks as an F1. Individual interviews with supervisors were conducted at their place of work. Interviews were semi-structured and followed a guide designed to explore: areas F1s had come to the supervisor for assistance with; skills the participant had observed being performed poorly; and problems they encountered due to their F1s being unprepared. Interviews lasted an average of 53 minutes (range 25-80 minutes). Interviews were audio recorded and fully transcribed, with all identifiers removed.

The interview data were analysed using thematic analysis (Braun \& Clarke, 2006). Data from F1s and supervisors were analysed separately. The study researcher (JK) completed initial coding by identifying prevalent themes inductively from the data, with the purpose of developing a thematic description of the full dataset. Subsequently, a team of three researchers (AP, PC, CS) confirmed the initial development of themes, reported patterns in the data, and identified and explored deviant 
cases. Repeated scrutiny of transcripts and constant comparison refined emerging themes. A computerised indexing system (NVivo v8 - QSR International; Melbourne, Australia) was used to help manage, systematise and summarise data and analysis. Thematic analysis enabled identification of predominant themes present in the two datasets relevant to the research goal: identifying issues relating to the preparedness of newly qualified doctors during the early transition from medical student to F1. Although larger samples had been planned, early analysis of the data via constant reading and rereading of the transcripts, confirmed that data saturation was reached before the last interviews were completed.

\section{Results}

Themes are discussed in detail under three broad headings that arose during the analysis and best capture the areas prioritised by participants. These include: Making the transition to F1 - knowledge and clinical skills; Time management and prioritisation; and Team work and support. Selected representative data extracts to illustrate individual themes can be found in the supplementary web material.

\section{Making the transition to F1 - knowledge and clinical skills}

Supervisors felt that the majority of F1s were well prepared for their first role and, following a steep learning curve, were quick to pick up new skills and gain experience once they started the role. But when describing their first few days of work, F1s expressed high levels of stress and anxiety related to feeling responsible for making decisions about patient care, working alone and being the first point of contact for other staff. They felt the pressure of having to deal with other peoples' changing perceptions of their status and role. For some, the early stress led to a negative impact on health and wellbeing outside of work, with constant worrying about decisions made and tasks to be completed.

F1s reported confidence in history taking and record keeping. Areas they felt less confident in included diagnostic skills, clinical knowledge and decision-making. Diagnosis and treatment as an F1 was very different from the experience as a student where decisions had seemed clear-cut. Responding to emergencies was stressful for some F1s. Some felt that experience, such as shadowing in emergency scenarios, would have also helped them prepare for the F1 job. Those who had undergone life support training during their undergraduate studies or induction period found this very helpful in dealing with urgent situations. Some F1s felt very prepared to perform skills such as cannulation, whereas others felt they had had little practice during their undergraduate training and would have valued more practical experience of performing procedures on a wide variety of patients.

This was in line with the supervisors' perception that some F1s had been undergraduates in a largely passive environment, where many practical procedures were practiced on simulators. They felt that the increased roles of specialist nurses, phlebotomists and physician's assistants had led to medical students and F1s being unable to actively take part in procedures such as taking blood and cannulation. Supervisors felt that this 'de-skilling' had a negative impact on the confidence of some F1s to undertake procedures and meant that consultants or registrars now had to make up for this lack of experience and confidence. Supervisors felt F1s particularly lacked confidence in dealing with acutely ill patients with complex and multiple problems. Developing differential diagnoses during clerking was seen by supervisors as an issue for some F1s. Although able to take the patients' history, some were less confident about summarising the problem and determining next steps, and often looked to senior colleagues for help. Supervisors felt that not being given enough responsibility, fewer opportunities to make decisions and passing issues on to senior review, led to 
fewer opportunities to develop as a doctor. However, supervisors acknowledged that the F1 year is a trainee role where confidence naturally grew over time.

Many F1s were surprised at the high level of administrative tasks expected of them (e.g. discharge summaries, clerking, ordering tests, referring patients on, chasing up test results) and the low level of patient contact experienced. This was problematic early on if they did not know where to go for help or how to access the relevant paperwork. Writing succinct and accurate discharge summaries was a key skill supervisors highlighted as needing attention.

Many F1s felt underprepared in key areas of prescribing, such as knowledge of drug interactions and side effects, writing drug charts, and prescribing fluids for patients with multiple conditions. Supervisors concurred, feeling that F1s had inadequate general knowledge of pharmacology regarding drug groups, drug interactions and side effects; particularly cardiac drugs and insulin. Supervisors felt F1s were not double-checking medication or dosages but were prescribing on guesswork. However, they acknowledged that mistakes could happen for all doctors, and that it was important to pick them up and learn from them; with pharmacists and specialist nurses playing a key role in highlighting prescribing errors.

\section{Time management and prioritisation}

Time management was a common issue for new F1s, with some feeling overwhelmed and unable to cope with prioritising high workloads, a large volume of patients and dealing with multiple demands from colleagues. This was particularly so when on-call and was exacerbated in Trusts experiencing staff shortages. Initially, many F1s felt pressure to always say 'yes' to colleagues, making it difficult to carry out their work effectively. In addition, the demands of the job sometimes conflicted with shift working, where participants found they needed to work much longer hours to complete tasks and not pass it on to others at handover. Some recognised that poor time management had an effect on patient care.

Similarly, supervisors emphasised how time management and prioritising skills were essential for effective working, particularly given the move to limited hours and shift working. They felt that many F1s initially lacked the ability to prioritise tasks, especially if they felt pressure to be overly accessible to colleagues. Supervisors believed that these skills were related to personality issues, as well as training. Poor time management skills led to a knock-on effect for colleagues who had to complete tasks not carried out during the day. Both supervisors and F1s felt that the ability to time-manage developed with experience. Supervisors highlighted their views that service and training had been negatively affected by the introduction of the European Working Time Directive (EWTD), which introduced into UK law a 48-hour week from August 2009. They felt this led to F1s having fewer opportunities to gain wide experience. Additionally, they believed that the multiple handovers necessary under new rotas led to F1s having less responsibility or sense of duty towards their colleagues, and fewer opportunities to experience ownership of tasks. Supervisors felt the EWTD resulted in a lack of continuity in patient care; which was detrimental to F1s training and development, as well as patient care. Professionalism, motivation, commitment and continuity were seen as vital markers of 'good' doctors by supervisors. Initiative and taking responsibility for their learning and development were also essential components for progress.

\section{Team working and support}

The majority of F1s had never felt part of the working team while they were on student clinical placements because they moved between clinics and wards. For some, this meant they had to learn how to operate within a team environment. Working within and across multi-professional teams was 
difficult for some in early days of work, as F1s did not feel that they had any position of authority with colleagues to, for example, request tests and make referrals.

Most supervisors felt that F1s' communication skills with patients were well developed, but skills such as assertiveness within a challenging team environment needed further development. Supervisors noted the modern NHS requires management and leadership skills, but felt these were not being taught at undergraduate level. Nevertheless, they felt that with support and encouragement F1 s could quickly become confident in their role and become valuable team members.

Access to support varied dependent on the team F1s were working with. Those F1s who were highly supported in their department reported less stress compared with those who were left to work alone without assistance. F1s had less support during weekends and night shifts, as well as periods of staffing shortages; these were often the most stressful periods early on. Additionally, when working alone, F1s felt that they were missing out on valuable feedback about their performance, which would have helped them develop their confidence to perform tasks. If advice or help was needed in the early weeks F1s would often go to their peers or second year Foundation doctors in the first instance. When they required senior support some F1s felt a lack of confidence in approaching consultants. A small number of F1s reported very difficult working relationships, with little support and guidance available. The need to assert themselves with senior colleagues could cause stress, as many F1s felt that there was an expectation that they would cope.

Supervisors reported F1s seeking help from them in areas including: specific patient care issues, medication, managing complex patients, reassurance of decision-making, time management and prioritising, managing the stress of increased responsibility, problems experienced with colleagues, and ethical issues such as consent and resuscitation. However, for day-to-day clinical advice and support supervisors felt that there was a hierarchy involved, where F1s would look to their peers or to registrars before accessing a consultant. As a consequence the consultant would rarely be the first point of contact for F1s. Failure to escalate up the authority chain worried supervisors.

The level of supervision available varied by Trust and department; in some departments F1s were an essential part of service provision, while in other posts they were supernumerary. This impacted both on the level of responsibility F1s held and the amount of support available. Those F1s who had a lower level of independence and responsibility in their first rotation felt less prepared for their second rotation. Supervisors felt that more areas for concern occurred when doctors were working out-of-hours. During these times F1s would often be working alone and there would be less senior support and supervision available.

Some supervisors felt in their current role they were unable to accurately assess their F1s' competencies. This was as a result of less contact with F1s within the clinical setting due to changes in F1 training and shift working and a separation of the day-to-day work from the training. Among other things, this made it difficult to recognise and deal with failing trainees.

Before beginning their post in August, local F1s were required to attend the Preparation for Professional Practice (PfPP) week, organised by the EAFS, which aims to prepare F1s for their new role. It offers the opportunity to get early questions answered during this period of anxiety, and includes formal training and a handover period where F1s shadow the outgoing F1. This shadowing is similar to undergraduate shadowing, but during PfPP the F1 is employed by the Trust and provisionally registered with the General Medical Council enabling them to work as a fully functional trainee doctor and enables them to do their new job alongside the current F1. F1s also underwent a 
Trust induction; a mandatory process whereby all new employees are introduced to the environment and employment policies of their new position. Additionally, at the start of each of their three rotations F1s received an induction for their department, introducing them to the specific department, its personnel and processes, and their position within it.

F1s found PfPP to be extremely valuable, particularly the shadowing component. Many would have liked more time gaining this experience, within a variety of settings and at the beginning of each of the three rotations. However the shadowing's usefulness depended on several factors. Shadowing was more useful in the morning when ward rounds were taking place. F1s who were able to shadow their own job felt at an advantage when starting. The usefulness was also dependant on the person they were shadowing. Departmental inductions varied between specialties and were generally not useful. F1s would have liked departmental information about: how departments worked, the clinical and non-clinical teams, where everything was, how individual consultants liked to do things, who to go to for help, processes at night, electronic discharging of patients, how to request investigations, being on call, the bleep system, and clear information on what their roles and responsibilities would entail.

\section{Discussion}

This study reports views of both F1s and supervisors on the preparedness for practice of newly graduated doctors entering the UK Foundation Programme. The results confirm findings of other studies in that there remains a need for better management of the transition from student to junior doctor. There were areas where the majority of both F1s and supervisors felt that F1s were underprepared. But it is important to recognise that supervisors were generally satisfied with F1s' performance. Most reported a satisfactory level of confidence in F1s with regard to patient safety, and felt that by the end of the first four month rotation F1s have gained in confidence and are usefully contributing to their team.

The major challenge in patient care was in dealing with complex cases of patients with multiple pathologies in contrast to the typical cases of single pathology they encounter as students. There was a consistent call for more realistic and continuing exposure to patients during the clinical placements. More widespread use of simulation, including multi-professional scenarios may lead to graduates being better prepared.

One area of weakness raised by both F1s and supervisors was prescribing. It is too simplistic to suggest that it is solely due to a lack of knowledge, as the problem persists despite the trainees in this cohort having been subjected to active interventions by medical schools to improve the teaching of prescribing. The response to this has been to introduce a national Prescribing Safety Assessment in an attempt to drive up learning. It is, however, unrealistic to expect F1s to be confident in prescribing as legally they are unable to prescribe until they graduate so cannot undertake realistic practice as students. This needs to be recognised by their clinical supervisors and other staff and appropriate support put in place, particularly when F1s are working at night and less back-up is available.

The positive impact on confidence and competence afforded to trainee doctors previously when they became active members of a ward team on starting work (Lempp et al., 2005) has been lost in the changes to working patterns due to the EWTD. The restriction on working hours has left F1s with fewer opportunities to practice skills and to follow the patient's journey. It also exacerbates problems of time management and prioritisation of tasks, with F1s failing to recognise which tasks are urgently important. The lack of continuing responsibility for patient care may encourage the deprofessionalisation of newly qualified doctors. This may manifest as a reduced sense of duty to 
colleagues and less team-working and co-operation. The loss of the traditional 'firm' has led to a greater need for the development of team-working skills, such as advanced communication and negotiation skills, and understanding of team roles. Additionally, medical students in the UK are becoming less involved in patient care. Routine tasks previously delegated to final year students is now done by non-medical staff and clerking of routine admissions increasingly takes place in preadmission clinics. Students are being side-lined into the role of observers, which is problematic given evidence that prior clinical experience reduces the stress associated with the transition from student to F1 (Brennan et al., 2010).

In response to the continuing challenges of managing the transition into practice the GMC has introduced a requirement in Tomorrow's Doctors 2009 (GMC, 2009) that all students must undertake a student assistantship in final year. During the assistantship they will be expected, under supervision, to fulfil all of the tasks of an F1 including taking responsibility for the continuing care of a group of patients. Student assistantships were still in the early stages of implementation when the doctors in the current study were in final year. It remains to be seen whether this is sufficient to improve the performance of F1s in the early weeks of their posts. The existing evidence suggests that the closer undergraduate medical education mirrors what F1s will face in their work environment, the better prepared they will be (Tallentire et al., 2011b). However, it may be that the significant psychological factor is the transition to taking personal responsibility for the care of the patient and this cannot be simulated effectively.

One limitation to this study is selection bias; recruitment was focused on those who were interested and available during the study period. Additionally, the research was carried out in the East of England region where some of the study sites were small, local hospitals in a semi-rural setting and the population includes lots of elderly patients; this may present different challenges for F1s compared to those working in inner-city hospitals. This may limit the generalisability of the findings. The sample of clinical supervisors mainly comprised male supervisors, so if there are any gender biases in supervisory relationships the findings could be affected due to this imbalance. This gender balance contrasts with the response from F1s, where there were more female participants.

However, this reflects current demographics regarding numbers training as doctors, where in recent years the number of female trainees has exceeded the number of male (Gibson \& Bowater, 2011). In both groups, the sample size provided enough data to reach saturation, which makes the recommendations provided worth exploring by those involved in training medical students and F1s.

\section{Conclusion and recommendations}

In conclusion, the findings give rise to a number of recommendations, as outlined below, which could improve the experience of newly qualified doctors if implemented where needed:

- Ensure that student assistantships and shadowing include active participation in the clinical team and appropriately reflect the complexity of the F1s' duties; including practice of clinical skills, exposure to acutely ill patients with complex problems and simulation of emergency situations.

- Encourage development of clinical reasoning, and support F1s in identifying a differential diagnosis and determining appropriate next steps particularly in complex cases.

- Ensure F1s are adequately supported when dealing with patients who have complex problems and make such problems a learning exercise by enabling the F1 to work alongside the senior to solve the problem.

- Provide practice in how to appropriately manage time, including how to prioritise tasks.

- Provide students / F1s with life skills training to enable them to cope in the transition to working as an F1.

- Provide practice with paperwork and other administrative tasks. 
- Provide students with practice opportunities for patient handover, and train F1s to provide effective handovers appropriate to their department.

- Provide prescribing and pharmacology experience that goes beyond knowledge acquisition to include more knowledge application.

- Provide training on advanced communication skills: Interacting with senior colleagues, assertiveness skills, dealing with challenging team members, communicating with patients with complex problems e.g. deaf / blind / disoriented / frail older patients.

- Ensure there is a departmental induction which covers information that the F1 needs in order to perform their role in that department.

- Provide F1s with feedback on their performance.

\section{Practice points}

- Supervisors feel that F1s are generally well prepared for their roles and have few patient safety concerns, but F1s find their new level of responsibility challenging.

- F1s feel underprepared for the administrative components of their role, including time management and prioritisation of tasks. Supervisors also felt these skills could be improved.

- Clinically, F1s are anxious about diagnosis, decision-making, prescribing and acting appropriately in an emergency. Supervisors feel competence in prescribing needs attention.

- Supervisors feel that changes in working patterns, undergraduate and postgraduate training have affected F1s' ability to develop their skills. F1s believe more active involvement in clinical care and opportunities for shadowing during undergraduate training would improve the transition from student to doctor.

- Induction needs to provide information on the day-to-day work that F1s will encounter.

\section{Acknowledgements}

The authors would like to acknowledge Kate Steward's contributions, particularly in transcribing the interviews.

\section{Declaration of interests}

This article presents independent research funded by the National Institute for Health Research (NIHR) under its Research for Patient Benefit (RfPB) Programme (Grant Reference Number PB-PG0808-17193). The views expressed are those of the authors and not necessarily those of the NHS, the NIHR or the Department of Health.

\section{Notes on Contributors}

Joanne Kellett, BA, is a Research Associate at the Norfolk and Norwich University Hospital. Alexia Papageorgiou, BA, MSc, PhD is an Associate Professor in Clinical Communication, St George's University of London Medical School at University of Nicosia. Penny Cavenagh, BSc, MSc, PhD is Dean of Academic Affairs at University Campus Suffolk. Charlotte Salter, BSc, MSc, PhD is a Senior Lecturer in Health \& Communication at the Norwich Medical School. Susan Miles, BA, PhD is a Research Associate in Medical Education at the Norwich Medical School. Sam J Leinster, BSc, MD, FRCS (Eng \& Ed), SFHEA, FAcadMed is Emeritus Professor of Medical Education at the Norwich Medical School.

\section{References}

Bleakley A, Brennan N. 2011. Does undergraduate curriculum design make a difference to readiness to practice as a junior doctor? Med Teach 33:459-67.

Braun V, Clarke V. 2006. Using thematic analysis in psychology. Qual Res Psych 3(2):77-101.

Brennan N, Corrigan O, Allard J, Archer J, et al. 2010. The transition from medical student to junior doctor: today's experiences of Tomorrow's Doctors. Med Educ 44:449-458. 
Brown JM, Watmough S, Cherry MG, Fewtrell R, et al. 2010. How well are graduates prepared for practice when measured against the latest GMC recommendations? Brit J Hosp Med 71(3):159-63. General Medical Council. 2009. Tomorrow's Doctors. GMC: London.

Gibson, S, Bowater, L. 2011. The shifting landscape: how undergraduate students have changed. In: The changing face of medical education. Cavenagh P, Leinster SJ, Miles S (eds), Radcliffe, Abingdon. pp51-63.

Goldacre MJ, Taylor K, Lambert TW. 2010. Views of junior doctors about whether their medical school prepared them well for work: Questionnaire surveys. BMC Med Educ 10:78.

Harding S, Britten N, Bristow D. 2010. The performance of junior doctors in applying clinical pharmacology knowledge and prescribing skills to standardized clinical cases. Brit J Clin Pharmaco. 69(6):598-606.

Illing J, Morrow G, Kergon C, Burford B, et al. 2008. How prepared are medical graduates to begin practice? A comparison of three diverse UK medical schools. [http://www.gmc-

uk.org/FINAL How prepared are medical graduates to begin practice September 08.pdf 29697 834.pdf] (last accessed $11^{\text {th }}$ February 2014).

Kilminster S, Zukas M, Quinton N, Roberts T. 2011. Preparedness is not enough: understanding transitions as critically intensive learning periods. Med Educ 45:1006-15.

Lempp H, Cochrane M, Rees JA. 2005. A qualitative study of the perceptions and experiences of PreRegistration House Officers on teamwork and support. BMC Medical Education 5:10.

Matheson C, Matheson D. 2009. How well prepared are medical students for their first year as doctors? The views of consultants and specialist registrars in two teaching hospitals. Postgrad Med J 85:582-9.

Tallentire VR, Smith SE, Skinner J, Cameron HS. 2011b. Understanding the behaviour of newly qualified doctors in acute care contexts. Med Educ 45:995-1005.

Tallentire VR, Smith SE, Skinner J, Cameron HS. 2012. The preparedness of UK graduates in acute care: a systematic review. Postgrad Med J 88:365-71.

Tallentire VR, Smith SE, Wylde K, Cameron HS. 2011a. Are medical graduates ready to face the challenges of Foundation training? Postgrad Med J 87:590-5.

Teunissen PW, Westerman M. 2011. Opportunity or threat: the ambiguity of the consequences of transitions in medical education. Med Educ 45:51-9.

The UK Foundation Programme Office (UKFPO). Foundation Programme Annual Report 2012: UK summary [http://www.foundationprogramme.nhs.uk/pages/home/keydocs] last accessed $2^{\text {nd }}$ October 2014. 


\section{Supplementary web material for the article:}

\section{"The preparedness of newly qualified doctors - Views of Foundation doctors and supervisors" Joanne Kellett, Alexia Papageorgiou, Penny Cavenagh, Charlotte Salter, Susan Miles \& Sam J Leinster}

A number of themes were identified from analysis of the interviews with first year Foundation doctors (F1s) and clinical and educational supervisors. These fell under three broad headings: Making the transition to F1 - knowledge and clinical skills, Time management and prioritisation, and Team working and support. In this document selected representative data extracts are presented to illustrate the themes under these headings. Quotes are identified by the participant / focus group number and whether the participant was a Supervisor (all one-to-one interviews) or F1 (either oneto-one interview, or focus group).

\section{Making the transition to F1 - knowledge and clinical skills}

F1s had found the transition from medical student to F1 to be stressful, and represent a steep jump in responsibility. Supervisors felt that F1s were generally well prepared and picked up skills and experience over time. Both supervisors and F1s commented on the importance of relevant experience whilst at medical school for helping them to be prepared. F1s commented on the difference between the clear cut situations they were exposed to at medical school versus the complex patients they faced in practice, particularly in emergency situations. Supervisors felt that not being an active participant during training negatively impacted on confidence and competence. F1s felt unprepared for the large administrative component of their new role, and supervisors felt that F1s were not prepared for writing discharge summaries. Both F1s and supervisors commented that aspects of prescribing skills are an area where F1s needed to be better prepared

- Learning over time with experience

"I think seventy percent of them are very well prepared but there is room for improvement. It's like apprenticeship...the more you do that job the better you become at it." (Supervisor 021)

"At the end of their attachment, they become very confident... when they present the case and the plan for actions, they already know it, there's no need for us to interfere an awful lot." (Supervisor 001)

- Responsibility and decision making

"The actual reality of being the doctor I found it quite a transition, to suddenly be the responsible person. People are asking your advice, it's quite a step. I remember the sister on my second day, there was a patient who needed a fluid challenge (a rapid infusion of intravenous fluid) and I said 'oh what do we normally give' and she [said] 'you're the doctor, you tell me', and that took me back a little bit. But I can see why she did it but on that day it was, 'oh I don't know what to do'." (F1, Interview 1)

"You've gone home and sometimes it's hard to forget and I have actually phoned up someone...at two in the morning because I couldn't sleep just to check some bloods that I'd already checked but I wanted to check that I'd checked the right bloods." (F1, Focus Group 5)

"It's things you do as a med student, you do them in a scenario in an OSCE station and they're like 'so this patient has low sats' and you're like 'hmmm, I would do this', but when you're sitting there and someone's going blue in the face in front of you, you're like 'oh my god, what am I going to do now?'” (F1, Interview 4) 
"More often than not now you'll get a history and examination and then they'll just stop and I'll go 'And? What do you make of it?' It's almost as if they're waiting for me to come up with a diagnosis and they should have done that in their clerking of the patient and coming up with a management plan as well, they seem to stop short of the differential diagnosis and the management plan."

(Supervisor 005)

"The greatest worry is [that]...everything should be a senior review, so there isn't that willingness to take a history, do an examination, come to a diagnosis, and then, within obviously a patient safety framework, implement treatment. There's an awful lot of deferral...where there is such an expectation of cover that actually in the F1 year, some F1s hide and don't make decisions." (Supervisor 012)

- The value of appropriate experience during training

"They teach us the clear cut situations in medical school but in reality it's never clear cut and that just makes it much more difficult." (F1, Focus Group 1)

"[We need to practice] more skills on difficult patients...so not just the 16 to 20 year olds with the huge veins, some old ladies with the fragile veins. You don't tend to practice [on] those people when you're a medical student; they're the people that take the time when you're a doctor." (F1, Interview 1)

"I had a rotation in urology as a med student so I had five weeks' worth of sticking in catheters... basically being an F1 which was a really good experience." (F1, Focus Group 7)

"The ALERT [Acute Life-threatening Events: Recognition \& Treatment] course...allows all of us a tool to use, and the ILS [Immediate Life Support], so when you get called into a resus [resuscitation] you just know what your role is to perform and you know where you should be and you know what piece of equipment to come out of the crash trolley and you can be really, really helpful and it's very rewarding." (F1, Interview 2)

"I don't feel very prepared for cardiac arrest just because I've never done a job where I carry the cardiac arrest bleep. I never actually saw a full blown arrest. I think maybe a day spent shadowing someone carrying the cardiac arrest bleep specifically might be useful." (F1, Focus Group 4)

"I think the problem is that students are no longer allowed to undertake practical procedures. That's a big difference compared with my own training forty years ago." (Supervisor 010)

"As a consultant now, I'm doing jobs I did as a house officer. It is very much more a hands-on consultant-led service because the de-skilling has started. I think people are less prepared when they start and ... fall further and further behind because they don't get the experience that we did." (Supervisor 018)

"The enhanced role of the nurse has taken a lot of roles that were traditionally always done by the house officer and as a result I think it has dented the confidence of F1s." (Supervisor 014)

- Administrative tasks

"There are days when I'm on the wards and I don't even take out my stethoscope and I don't realise until the end of the day when I'm looking for it to put it away that I haven't used it. You sometimes 
barely touch a patient...It's only if there's a sick patient that you'll get called, or if you're on call. Other than that you're just swanning around, chasing results, ordering tests." (F1, Focus Group 3)

"I didn't know anything about sending people home at medical school. All this stuff that I'm supposed to pick up and fill in forms for [I had] no idea, all new and that's such a huge part of my job." (F1, Focus Group 5)

"I don't see that they've got any skills at all about how to write discharge letters and it is the first thing that they have to do on their own and they have to do it from the first day, is write a discharge letter and from what I can tell, they haven't had any training about what should go in the discharge letter, who the discharge letter is meant for, and they write these essays which is not appropriate." (Supervisor 004)

\section{- Prescribing Skills}

"[When] monitoring heart failure when do you dial up the furosemide, when do you dial down the furosemide because you don't do that as a medical student, you think 'oh this sounds like heart failure' and that's it, your job ends, you've identified something and someone else does all the scribbling and the adjusting and the managing." (F1, Focus Group 3)

"If someone has low blood pressure what do you do? If someone's got high potassium what do you do? Because you talk about it in lectures but you don't actually go through the 'this what you prescribe and this is how you prescribe it' side of things. You know you have to give [medication] but you don't know how on earth to give it." (F1, Interview 1)

"I would say $50 \%$ of them can't write a prescription for insulin, so, given the prescription from their GP, they then can't translate that into a hospital prescription for the correct amount of insulin....and most of them can't identify an insulin syringe [and] if you use the wrong type of syringe for insulin you give completely the wrong dose. (Supervisor 004)

"The only difficulty that we had in the last six months was with a medication error...The F1 took a list of the medication and wrote up a dosage that was about ten times the dose that it should have been and was double, twice daily rather than the once daily that it should have been... The nurse picked it up, recognised it and alerted us...The F1 was busy, was talking to somebody else, the phones were going, bleeps were going, and it was an honest, simple mistake that as soon as it was recognised, they also saw that they had made the error, recognised it, tried to recognise that they would try in future to concentrate more on the task in hand and therefore not make the same mistake." (Supervisor 003)

\section{Time management and prioritisation}

Both F1s and supervisors felt that F1s' time management and prioritisation skills could be improved. F1s struggled with managing competing demands on their attention and prioritising large numbers of patients. Supervisors additionally commented on the impact the European Working Time Directive (EWTD) had had on collaborative working and continuity of patient care, through changes in working patterns. Additionally, they commented on professionalism including personal motivation and commitment as important characteristics of a 'good doctor'.

\section{- Time management and prioritisation}

"It's when you're wanted in more than one place at the same time with say a sick patient on the ward but you're also clerking people in A\&E that are breaching [exceeding the 4 hour waiting time target] and you're trying to get a cannula into someone and it's not going well and that's holding you 
up from doing other stuff and you're being bleeped at the same time, and every time you go to answer your bleep you're having to apologise to your patient." (F1, Focus Group 5)

"It was the sheer volume of patients and the number of theatre lists a week... someone has to be there and if one person went home it just meant the others would have to stay 'til ten instead of nine so we all tended to stay late." (F1, Focus Group 6)

"The ability to manage your time effectively at work in the interests of your patients or to organise the requesting and collation of test results in the interests of your patients, is as important as being able to put a cannula in or to take a good history...you can take a brilliant history and put the cannula in but if you don't organise the test results to be back when they're needed for the effective and efficient running of that service which exists for the patients, it's just as important...let's remember that being a doctor is a very practical, mundane thing." (Supervisor 019)

“The F1s who aren't prepared for the business of ward life don't seem to be able to prioritise and don't seem to be able to filter through and say 'right, I've got to see the sickest people first' and then have the skills to define what makes somebody the sicker patient and it keeps coming back to the organisation, efficiency, timing, that ability to cope under pressure and ability to recognise a sick patient because...that's what you want from your F1s, because they're the person who spends most time on the ward." (Supervisor 012)

"Some of them hit the ground running and are obviously very good in terms of organisational skills...Some of them are exceptionally good from day one and others are pretty awful. I think it's just more a personality issue than what their good attributes and not so good attributes are [from] training." (Supervisor 010)

"I don't think we prepare F1s well enough for the world of work. Just being an employee within a huge, busy, stretched organisation.... what it means to be a professional, effective, efficient employee within this service, within this organisation, within this Trust...A lot of trainees flounder because nobody's given them clear guidance or expectations." (Supervisor 019)

\section{- The impact of the EWTD, and professionalism}

"The European Working Time Directive has thrown up all sorts of difficulties...the junior doctor quite rightly feels that they should only be working the number of hours that they're paid for and I'm very sympathetic to that, but at the same time they have trained to be professionals and I think that where the need arises for emergency care, for example, or just a professional duty to finish the job means that people should have the responsibility and self-directed learning to continue a task that they might be doing to finish what they're doing before clocking off." (Supervisor 003)

"As a result of that leaving at five o'clock there are some who don't think collaboratively and facilitatively when thinking about their colleagues who are going to be working that evening...the good $\mathrm{F} 1$ will be the person who tries to do all their jobs and gets all the little things done. The crazy thing is at five past five the on call F1 will get called to do the IV fluids, the drug charts, all the basic things that should have been done by the team during the day but because the F1 either doesn't want to or hasn't found the time to do so has just left those." (Supervisor 012)

"They often don't feel that the patients are theirs...If you clerk them in and you don't seem them again because you're going off duty or you're off the next day or you're on twilights on a different ward, you've lost that ability to establish that rapport and empathy with an individual rather than a patient, and you haven't seen the effects that your work has contributed to the management of that 
patient.... whether your thoughts were right or wrong...so it's very much in a vacuum, there's no continuity which is not good for anyone but it's particularly not good for F1s...[as it] doesn't give you the patient journey." (Supervisor 014)

"Some doctors...they're almost ahead of you in anticipation and others are sitting there, or standing there knowing nothing...I think two thirds of it is motivation and personality because that's really what gets them going during their student days and gets them involved and therefore they learn better...it gets down to motivation of the junior doctor. Some of them take it seriously and are there all the time including the handover rounds and into the evening and others just think it's part of medical school life and drift away at three in the afternoon and in a way that's a big red flag, if they do they're not really going to do terribly well later on." (Supervisor 010)

\section{Team working and support}

F1s commented on a desire for more experience of working in teams during undergraduate training; noting difficulties working within and across teams during the early days of work. They also commented on difficulties they had experiencing in accessing support and missing out on valuable feedback due to not working closely with seniors. F1s additionally commented on the value of a useful induction at the start of the F1 year in each new department; including the value of appropriate shadowing experiences during the Preparation for Professional Practice week at the start of their $\mathrm{F} 1$ year as supporting them during their early days of work. Supervisors highlighted the importance of F1s accessing support when they needed it. They also commented on the need for assertiveness, management and leadership skills. Additionally, they commented on difficulties in assessing F1s due to having less contact with them as a result of the change in working patterns.

\section{- Team working}

"Being part of a firm on placements...might well have improved some of our experiences because you are part of a team and I think that in our placements you never really did join one team, you just spent time in clinics, on the wards, moved about a bit." (F1, Focus Group 8)

"On my first week I tried to request some $x$-rays which the registrar had asked me to request and the radiographers weren't having any of it and basically completely refused ... I was really upset ... but now I would know how to stand up for myself and get things that are reasonable done." (F1, Focus Group 1)

"I think that's probably the single most important issue in terms of making doctors ready for being FY1s...you've just got to get them in and working really as part of the team rather than just hangers on that just drift around and turn up for clinics and the odd ward round." (Supervisor 010)

\section{- Support}

"I think I felt more embarrassed to ask for help with something in that I felt these were jobs that I could do and should do and if I was on call and I was really busy I thought 'oh that's just tough and I should get on with it'." (F1, Interview 3)

"You want to be told people think your communication skills are good or this seems to be the area that you should focus in on most, especially in that first rotation [but] nobody talks to you, nobody tells you how you're doing and you have to gauge by the fact that people aren't telling you what you're doing [is] wrong that you're doing stuff right". (F1, Interview 2)

"It's emphasised again and again if they're having trouble to call somebody senior. If the senior is busy, call the next senior after that, right up to consultants and they're told that consultants do not 
mind being called, they'd rather be called than not...I do get involved in lots of the disasters...you look in the notes and it's been one F1 to another F1 to another F1 and it's never gone higher." (Supervisor 014)

"[It's important that] they can escalate a problem to the right person who can deal with it and they don't feel afraid of doing that...[They need] assertiveness in order to ring intensive care outreach team or not just the one person they've met, but even the consultant at home if it's that consultant's patient and...if they don't get any help, just go on and get it." (Supervisor 009)

\section{- Leadership and management skills}

“Even at an F1 level they are leaders...they're managing workloads, they're managing priorities... and if you have a multi-disciplinary meeting to discuss an elderly patient who is going home...often people will look to the doctor... to lead the discussion, to chair it...So even at a very early stage, a very junior doctor [will] have quite strong leadership responsibilities and that is not taught." (Supervisor 003)

"There's too many doctors still who see management as different to medicine...Every one of them has to manage resources and until they are resource aware they won't understand why people moan at them for doing too many investigations; it's not to do with clinical skills, it's making good use of resources." (Supervisor 006)

“They don't know how to delegate, they don't know why teams fail to work...Now if you could teach the F1s 'you're joining a healthcare team, a team has its strengths and its weaknesses, you're part of a team'. They do tend to come in as a sort of 'oh I'm just the F1'. No, you're not just the F1, you're the glue that holds our department together, don't underestimate yourself...Very few of us now work individually." (Supervisor 006).

\section{- Difficulties in assessing F1s' performance}

"It's more difficult to fail because to really get an idea how someone is performing you need to see them day in, day out...this illusion that you can somehow separate the service and the work from the training and then you assess results of training out of the context of the daily work, and that doesn't work. If you work in a team, you work in a team for four months then you know if people show up on time, you know if the clerking is right, you know if they do what's important."(Supervisor 008)

"It's far easier to pass someone in medicine than to fail them... There's [a] phrase, they have 'no concerns'. If you don't interact with them you don't have any concerns because you don't see them. Yes, I did my weekly ward round and they were there and they washed their hands and they shaved and they weren't wearing anything inappropriate, yes l've got no concerns, off you go." Supervisor 013)

- Induction

"When I was starting...my former F1 used to just show me exactly how to order tests. She made me do it a few times and she used to tell me exactly how to do things and how to print out things in the right way to make it more time efficient...otherwise I would have been completely lost I think." (F1, Focus Group 6)

"I remember trying to shadow my F1s, saying 'Is there anything I can do?' And they'll be just like, 'No go away, I've just got boring stuff to do'." (F1, Interview 2) 
“Mine was in [Paediatrics], which was nine to five, don't do anything, no-one watches what you do, so I did an induction in not really doing a lot, shadowed not really doing a lot and then started on medicine which was the biggest shock to the system I've ever had." (F1, Focus Group 5)

"That first week [was] horrible because you feel like you're more a hindrance than a help in a way...if they could do basic orientation on the ward like 'this is where the paper is, this is where the needles are', that would really help". (F1, Focus Group 8)

"They should do...a standard sheet that's used in every department like 'this is the F1 position for Respiratory, we want you to be able to do this, this happens on a daily basis'." (F1, Focus Group 7) 